\title{
Body mass index-associated molecular characteristics involved in tumor immune and metabolic pathways
}

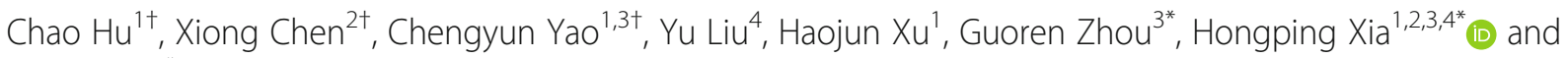
Jinglin $\mathrm{Xia}^{2 *}$

\begin{abstract}
Background: Overweight or obesity has been evidenced as an important risk factor involved in the incidence, mortality, and therapy response of multiple malignancies. However, the differences between healthy and obesity tumor patients at the molecular and multi-omics levels remain unclear.

Methods: Our study performed a comprehensive and multidimensional analysis in fourteen tumor types of The Cancer Genome Atlas (TCGA) and found body mass index (BMI)-related genes in multiple tumor types. Furthermore, we compared composite expression between normal, overweight, and obese patients of each immune cell subpopulation and metabolism gene subset. Statistical significance was calculated via the Kruskal-Wallis rank-sum test.

Results: Our analysis revealed that BMI-related genes are enriched in multiple tumor-related biological pathways involved in intracellular signaling, immune response, and metabolism. We also found the different relationships between BMI and different immune cell infiltration and metabolic pathway activity. Importantly, we found that many clinically actionable genes were BMl-affect genes.

Conclusion: Overall, our data indicated that BMI-associated molecular characteristics involved in tumor immune and metabolic pathways, which may highlight the clinical importance of considering BMl-associated molecular signatures in cancer precision medicine.
\end{abstract}

Keywords: Body mass index, Pan-cancer analysis, Molecular characteristics, Tumor immune microenvironment, Metabolic pathways

\footnotetext{
*Correspondence: zhouguoren888@126.com; xiahongping@njmu.edu.cn; xiajinglin@wzhospital.cn

${ }^{+}$Chao Hu, Xiong Chen and Chengyun Yao contributed equally to this work.

${ }^{3}$ The Affiliated Cancer Hospital of Nanjing Medical University \& Jiangsu Cancer Hospital \& Jiangsu Institute of Cancer Research, Nanjing 210009, China

'Department of Pathology in the School of Basic Medical Sciences \& The Affiliated Sir Run Run Hospital \& State Key Laboratory of Reproductive Medicine \& Key Laboratory of Antibody Technique of National Health Commission, Nanjing Medical University, Nanjing 211166, China

${ }^{2}$ The First Affiliated Hospital of Wenzhou Medical University, Wenzhou 325000, China

Full list of author information is available at the end of the article
}

(c) The Author(s). 2020 Open Access This article is licensed under a Creative Commons Attribution 4.0 International License, which permits use, sharing, adaptation, distribution and reproduction in any medium or format, as long as you give appropriate credit to the original author(s) and the source, provide a link to the Creative Commons licence, and indicate if changes were made. The images or other third party material in this article are included in the article's Creative Commons licence, unless indicated otherwise in a credit line to the material. If material is not included in the article's Creative Commons licence and your intended use is not permitted by statutory regulation or exceeds the permitted use, you will need to obtain permission directly from the copyright holder. To view a copy of this licence, visit http://creativecommons.org/licenses/by/4.0/ The Creative Commons Public Domain Dedication waiver (http://creativecommons.org/publicdomain/zero/1.0/) applies to the data made available in this article, unless otherwise stated in a credit line to the data. 


\section{Introduction}

Excess body weight, including overweight and obesity, is defined as abnormal or excessive fat accumulation that increases the risk of many noncommunicable diseases [1]. A large number of studies reported that excess body weight is associated with the cancer burden. Epidemiological studies concluded that excess body weight increases the risk of 13 cancers with sufficient evidence, including the esophagus, gastric, colon and rectum, liver, gallbladder, pancreas, breast, corpus uteri, ovary, kidney, meningioma, thyroid, and multiple myeloma [2]. Besides, studies also reported that excess body weight is associated with other cancers, such as lung, prostate, and hematologic cancers [3-6]. Some studies indicate that obesity affects the treatment response of tumor patients. Obesity could promote anti-VEGF therapy resistance in breast cancer by producing inflammatory and angiogenic factors [7]. And obesity promoted cancer resistance to chemotherapy in breast, pancreatic, and prostate cancer [8-10]. Although obesity heightened immune dysfunction and tumor progression, greater anti-tumor efficacy and survival were found in obese patients treated with targeted therapy and immunotherapy [11, 12]. Previous studies have proposed various mechanisms to clarify the relationship between excess body weight and cancers. Chronic inflammation and metabolic abnormalities are the most studied [13-16]. Effects of adiposity-associated alterations of inflammation and microenvironment are thought to affect multiple cancers types, such as gastrointestinal, breast, liver, and pancreatic cancers [10, 17-20]. Insulin resistance and hyperinsulinemia can stimulate tumor cell proliferation and promote the growth of colorectal, pancreatic, liver, breast, and endometrial cancers [21, 22]. Adipose tissue affects the synthesis and bioavailability of sex hormones and mediates the association between excess body weight and hormone-related cancers $[13,16]$.

Body mass index (BMI), defined as body mass in kilograms divided by the square of height in meters $\left(\mathrm{kg} / \mathrm{m}^{2}\right)$, is the most widely used anthropometric measure to estimate overall body fatness and strongly correlated with adiposity [23]. Some studies have reported some BMIrelated molecular patterns. For example, an obesityassociated cancer expression signature was defined in breast cancer [24]; gene microarray data revealed different signatures between obese and nonobese endometrial cancer patients [25]; PTEN loss resulted in PI3K pathway activation in nonobese patients, downregulation of $\beta$-CATENIN, and FOXO3A phosphorylation in obese patients in endometrial cancer [26], and DNA methylation pattern of excess body weight patients was changed in breast, colorectal, and kidney cancer [27-29]. However, these studies have been limited to individual genes, single-molecular data types, or single-cancer lineages.
The Cancer Genome Atlas (TCGA) has provided large-scale high-throughput molecular data with corresponding clinical data of multiple cancer types, which created an opportunity for researchers to systematically study the association between molecular data and BMI [30]. In this study, we performed a pan-cancer analysis to investigate the BMI-related comprehensive cancer molecular characteristics using these TCGA data.

\section{Materials and methods}

\section{Analysis of patient clinical information}

We obtained clinical information from TCGA-Clinical Data Resource (CDR) Outcome (https://gdc.cancer.gov/ about-data/publications/pancanatlas) and Broad GDAC Firehose (http://gdac.broadinstitute.org/), the patients with both height and weight information were retained for subsequent analysis. BMI was calculated by body weight in kilograms divided by the square of height in meters $\left(\mathrm{kg} / \mathrm{m}^{2}\right)$. BMI differences between male and female patients were compared by the Wilcoxon rank-sum test. Patients can be classified into three categories (normal, $\mathrm{BMI}<25$; overweight, $25 \leq \mathrm{BMI}<30$; and obesity, $30 \leq$ BMI) based on their BMI level, and survival difference between three groups was compared across all tumor types as well as individual tumor type with $p$ value calculated via log-rank test using the survival package in $\mathrm{R}$. And the clinical confounders such as age, gender, stage, and grade were controlled using multivariate $\mathrm{COX}$ analysis.

We obtained molecular subtypes information from TCGAbiolinks packages of Bioconductor. Furthermore, the BMI difference between different tumor subtypes was compared using the Kruskal-Wallis test.

\section{Analysis of mRNA expression and DNA methylation data}

We obtained normalized gene mRNA expression and gene DNA methylation $450 \mathrm{~K}$ data from the website of Firehose. The association between genes and BMI was calculated by propensity score weighting (PSW) method based on $P S W$ package in $\mathrm{R}$. The $p$ value was adjusted by Benjamini \& Hochberg method and genes with the adjusted $p$ value less than 0.05 were considered as BMIcorrelated genes; our method may miss few BMI-related genes after FDR control due to the limited number of tumor samples. Pathway enrichment analysis of selected BMI-correlated genes was applied using the clusterProfiler package. We also performed a Gene-Set-Enrichment analysis (GSEA) with the ranked gene according to the PSW and identified association between BMI and gene mRNA expression or methylation level by GSEA software 4.0 version and the significantly enriched pathways.

\section{Analysis of miRNA and protein expression data}

We download the miRNA expression data from the Firehose database and the protein RPPA expression data 
from The Cancer Proteome Atlas (TCPA) database (https://www.tcpaportal.org/tcpa/index.html). The PSW method was used to identify BMI-associated genes and the adjusted $p$ value less than 0.05 were considered as BMI-correlated miRNA or protein genes. To explore the potential functions of candidate miRNAs, we identified potential miRNA targets from the following experimentally supported miRNA-Gene interaction databases: miRTarbase, Tarbase, miRanda, miRDB, miRecords, and TargetScan. We then selected the candidate targets using two criteria: (1) the targets were in miRTarbase with strong evidence and (2) or in at least three of the other four databases. Pathway enrichment analysis was performed using these target genes.

\section{Analysis of somatic mutations and somatic copy-number alteration data}

We obtained the somatic mutation (SNV) data from TCGA Pan-Cancer Atlas and significant somatic copy number alterations (SCNA) from Firehose. To prevent the potential effect caused by ultra-mutated samples, we filtered out the samples with over 1000 mutations in their exomes, while the non-silent mutations with over $5 \%$ mutation frequency in a patient cohort were retained for subsequent analysis because of their potential biological significance and detecting power in analysis. Next, we divided the patients into two groups, normal (BMI < 25) and excess weight $(25 \leq \mathrm{BM})$. The PSW method was used to compare SNV and SCNA versus normal patterns between normal and excess weight group patients. The BMI-related alterations were identified at adjusting $p$ value (FDR) less than 0.1.

\section{Analysis of tumor-infiltrating lymphocytes and metabolism pathways}

To study the BMI-related tumor immune microenvironment, we used the single-sample gene set enrichment analysis (ssGSEA) method to identify the tumorinfiltrating lymphocyte subpopulations described in a previous study [31]. We first obtained genes related to specific tumor-infiltrating lymphocytes from the study, which include 28 immune cell types. For each patient, genes were ranked according to their log-transformed expression. The association was represented by a normalized enrichment score (NES). An immune cell subpopulation was considered enriched in a patient when NES $>0$ and FDR ( $q$ value) $\leq 0.1$. For metabolism pathways, we obtained seven metabolic super-pathway gene sets that contain main human metabolic processes from the Reactome database. We applied an analysis strategy similar to the immune cell subpopulation analysis to analyze enriched metabolism pathways in each patient. Fisher's exact test was used to compare enrichment patterns between normal and excess weight group patients.
We compared composite expression between normal, overweight, and obese patients of each immune cell subpopulation and metabolism gene subset. Statistical significance was calculated via the Kruskal-Wallis ranksum test.

Analysis of BMI-related clinically actionable genes and drugs The clinically actionable genes were defined as FDAapproved therapeutic targets and their corresponding predictor markers, which obtained from the TARGET database (http://www.broadinstitute.org/cancer/cga/tar get). We extracted the anti-cancer drugs and their target information from the DrugBank database.

\section{Results}

The BMI characteristics of TCGA samples

To characterize the specific molecular characteristics that are associated with body mass index (BMI), we selected 2715 patients across 14 tumor types that provided BMI information from The Cancer Genome Atlas (TCGA) project (Supplementary Table S1). Patients were divided into three categories according to the BMI (normal, BMI $<25$; overweight, $25 \leq \mathrm{BMI}<30$; and obesity, $30 \leq \mathrm{BMI}$ ). Eleven out of 14 tumors had more than half of excess body weight $(25 \leq \mathrm{BMI})$ patients, and endometrial carcinoma (UCEC) was the most significant contributor of excess body weight patients and also had the highest proportion across the 14 tumors (Fig. 1a). The total number of tumor cases with excess body weight was higher in females than in males (989/1471 in females vs. 768/1248 in men). UCEC was the largest cohort among female excess body weight patients, followed by cervical cancers (CESC) and colon adenocarcinoma (COAD). In contrast, the largest cohort among males was bladder carcinoma (BLCA), followed by kidney papillary cell carcinoma (KIRP) and hepatocellular carcinoma (LIHC) (Fig. 1b, c). No significant difference was observed between male and female patients' BMI values (Fig. 1d).

To gain insight into the prognostic role of BMI, we analyzed the survival differences of the three BMI groups by Kaplan-Meier curves across all tumor patients. Patients with higher BMI corresponds to longer overall survival times across all patients (Fig. 1e). Survival analysis was also applied to each tumor separately, and only in COAD, we observed significant overall survival differences and obese patients had a better prognosis than normal and overweight patients (Fig. 1f). Furtherly, the obese was independently associated with patient prognosis after adjusted potential clinical factors with multivariate COX analysis (Figure S1).

\section{BMI-associated mRNA expression and DNA methylation characteristics}

To characterize the BMI-associated gene mRNA expression and DNA methylation signatures, we performed a 

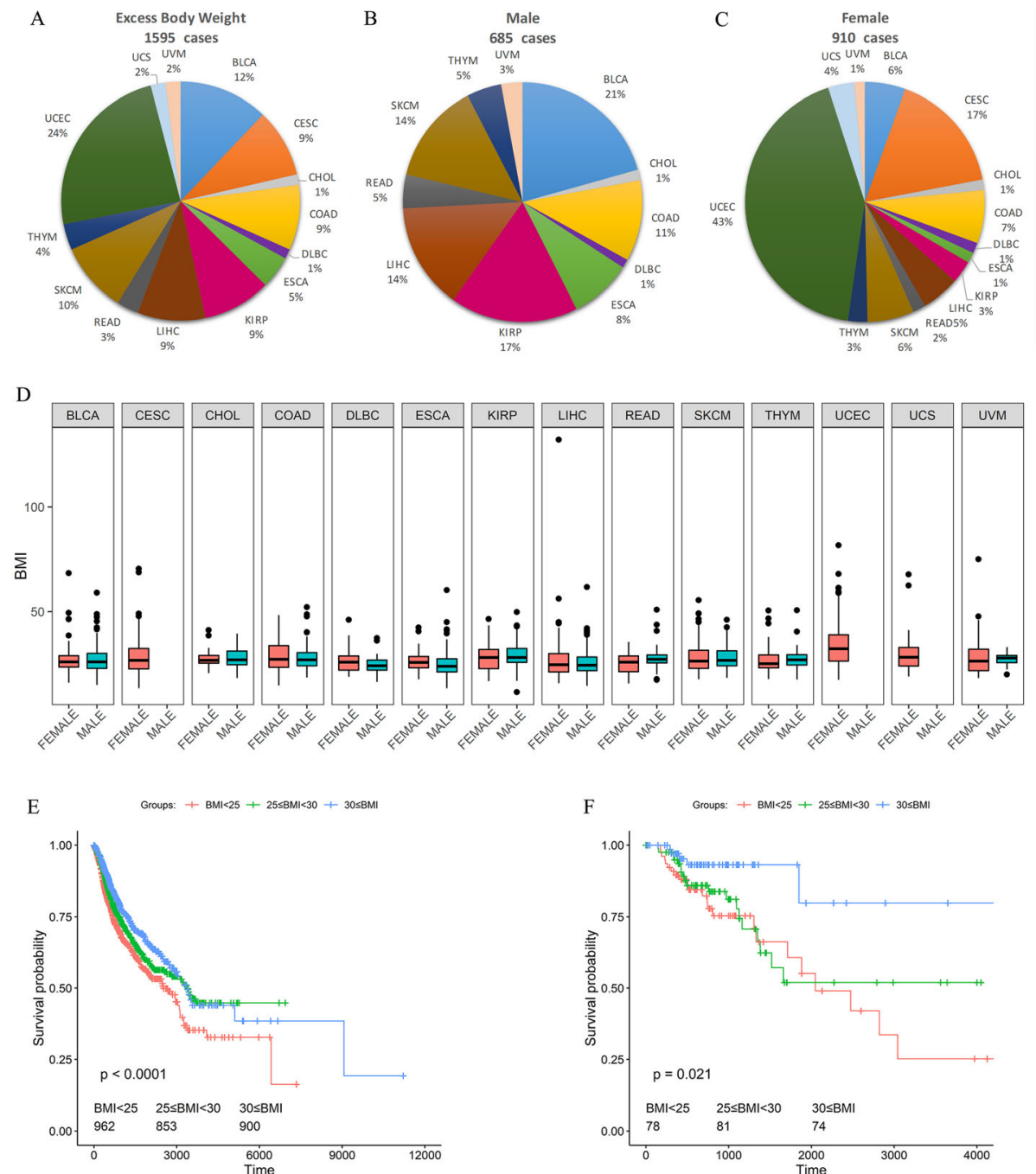

Fig. 1 The BMI characteristics summary of TCGA patients. a The proportion of each tumor in all excess weight patients. $\mathbf{b}$ Proportion of each cancer in male excess weight patients. c Proportion of each tumor in female excess weight patients. $\mathbf{d}$ Comparison of the BMI difference between male and female patients for each tumor type, no significant difference found. e Survival difference between different BMl groups across all tumor patients. $\mathbf{f}$ Survival difference between diverse BMI group in COAD. The correspondence between full names and abbreviations is provided in Table S1

PSW analysis on 14 TCGA tumor types. For mRNA expression data, we detected BMI related genes in 8 tumors and only esophagus cancer (ESCA) and UCEC identified abundant genes associated with BMI, and for DNA methylation data, we detected BMI-related genes in 4 tumors and only COAD and UCEC identified abundant genes (Supplementary Table S2). To understand the functions of BMI-correlated genes in tumors, we performed a functional enrichment analysis and identified the affected KEGG pathways. In ESCA, BMI-associated mRNA genes were enriched in many important tumor pathways involved intracellular signaling, immune response, such as PI3K-Akt signaling, ECM-receptor interaction, and B cell receptor signaling pathways (Fig. 2a). A previous study report that BMI-associated differential genes in endometrial cancers were related to cilium/microtubule or cell cycle and DNA metabolic processes. It is similar to our result in UCEC that the BMI-related genes mostly enriched in cell cycle and metabolism-related pathways, we also identified BMI biases of CST3, ADAMTSL5, and ADAMTSL3 as mentioned related to cilium or microtubule (Fig. 2b). BMI-associated gene methylation enrichment showed that BMI-related genes were enriched in metabolic or metabolic diseases, natural killer cell cytotoxicity, and cell adhesion pathways in COAD (Fig. 2c). And in UCEC, the BMI-related gene methylations were associated with digestion and metabolism, immune cell activity, and signal transduction (Fig. 2d). 


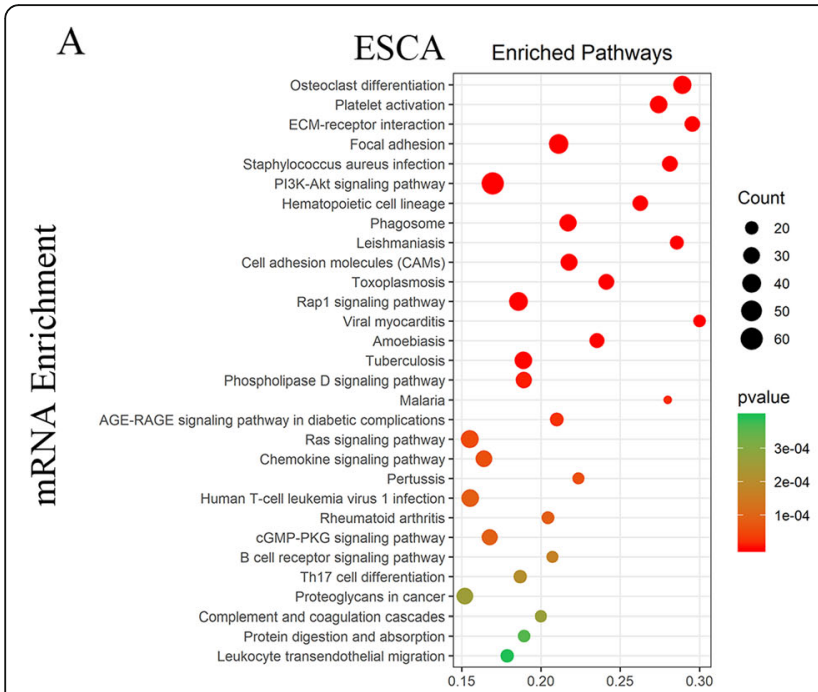

B
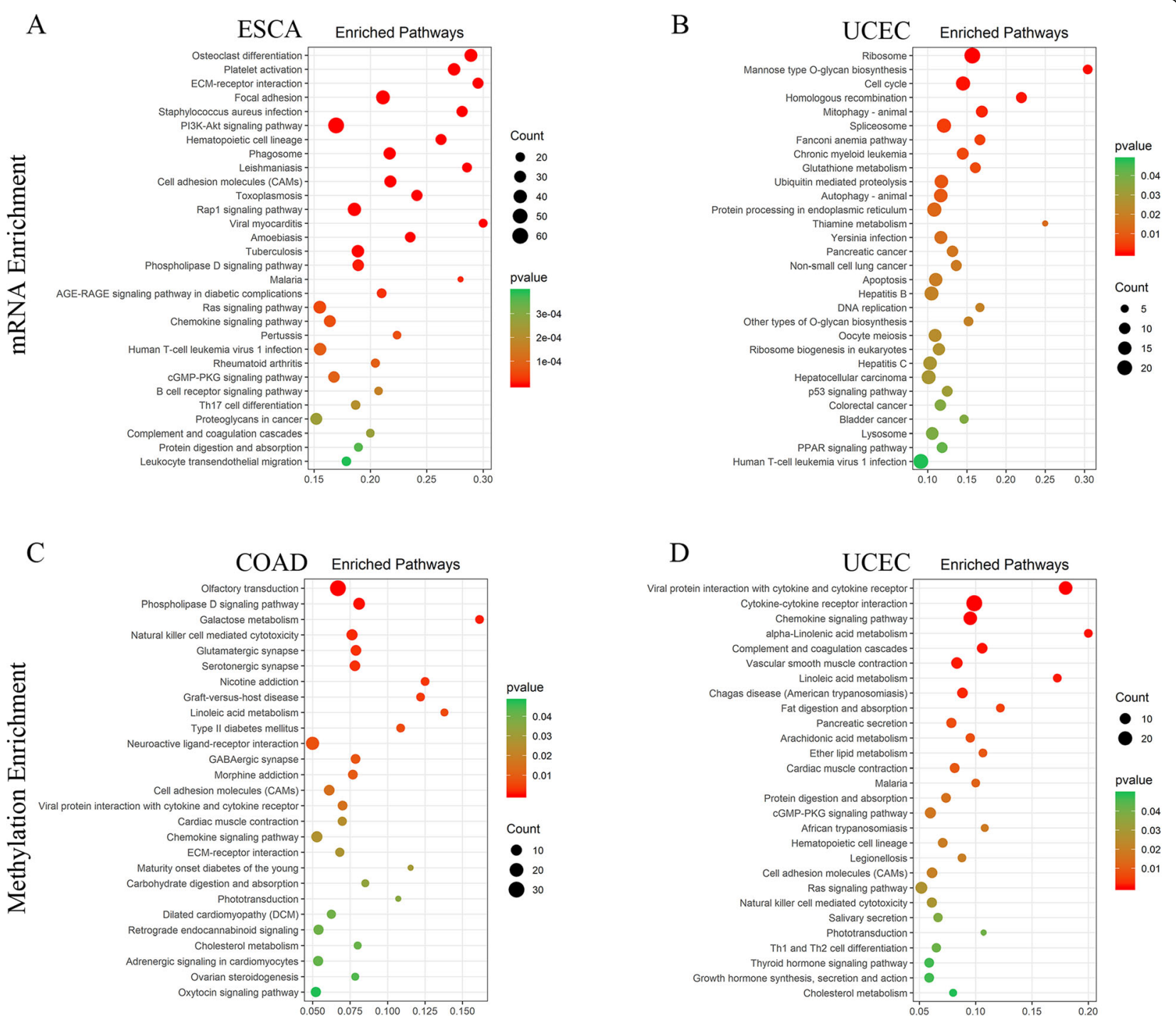

Fig. 2 Expression signature of BMI-associated genes in three strong BMI-related tumors. The top-enriched KEGG pathways of BMI-correlated mRNA genes in a ESCA and $\mathbf{b}$ UCEC. The top BMI-correlated DNA methylation genes enriched KEGG pathways in $\mathbf{c}$ COAD and $\mathbf{d}$ UCEC

We also combined colon and rectal cancer as colorectal cancer (CORE) because of their clinical similarities. PSW analysis identified $17 \mathrm{mRNA}$ and 1528 methylation genes associated with BMI in colorectal cancer. Pathway enrichment showed the genes were enriched in focal adhesion, cAMP signaling, and ECM-receptor interaction pathways (Figure S2A).

We also performed a Gene-Set-Enrichment analysis (GSEA) given the gene ranks according to the association between BMI and gene expression or methylation level and identified the significant enriched biological pathways. Combining the gene expression and DNA methylation GSEA enrichment results, we found that the enriched pathways could be divided into four functional groups (immune response, metabolism, signal processing, and other pathways). The immune response group includes allograft rejection, complement and coagulation cascades, hematopoietic cell lineage, $\mathrm{T}$ cell receptor signaling, and primary immunodeficiency pathway. The pathways of metabolism group include citrate cycle, fatty acid metabolism, glycolysis and gluconeogenesis, retinol metabolism, steroid hormone biosynthesis, and tryptophan metabolism. The signal processing group are several genetic and environmental information pathways that are important in cancer, such as cytokine-cytokine receptor interaction, ribosome, and DNA replication (Fig. 3). ESCA and UCEC mRNA genes positively related to the ribosome, and ESCA mRNA negatively related to immune pathways while UCEC methylation genes are positively related to 


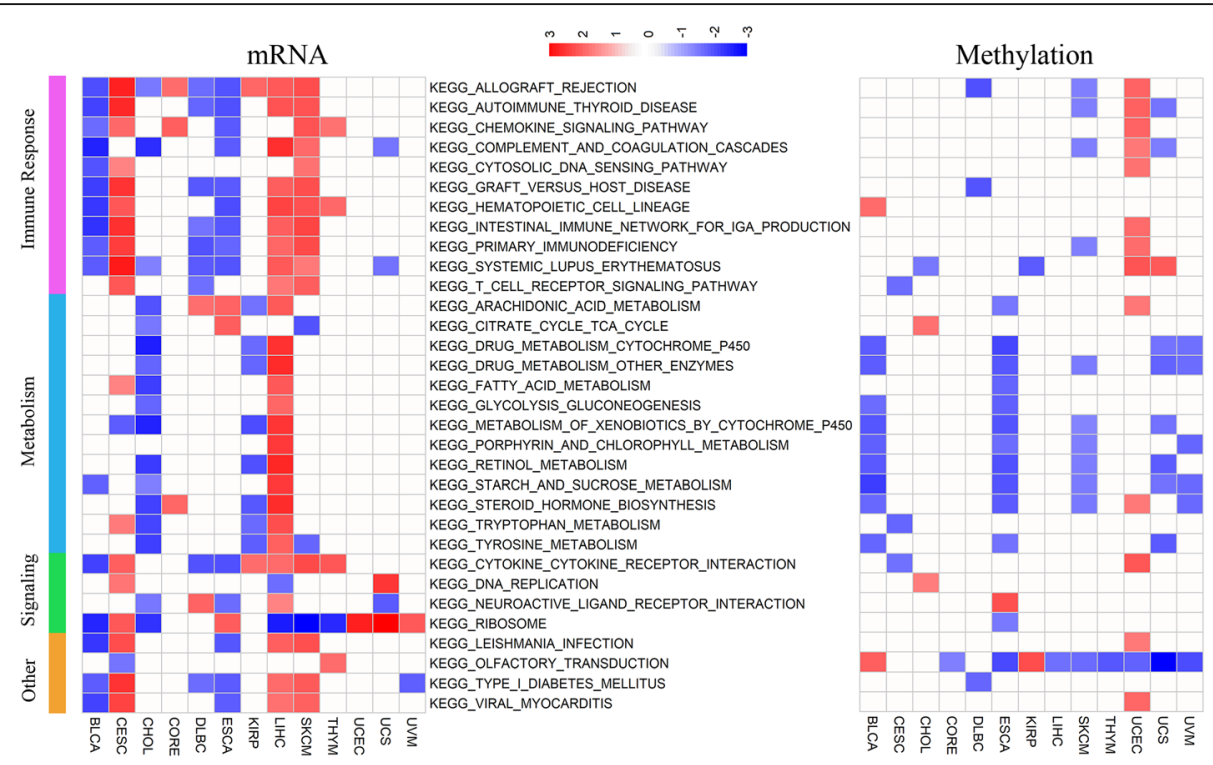

Fig. 3 Expression signature of BMI-associated genes across TCGA cancers. The enriched pathways identified via GSEA of ranked mRNA and methylation genes, the color of each square represents NES values of significantly enriched pathways, and white squares indicate no statistical significance. The different colors of the bar on the left indicate the function group pathways belong to

immune pathways, it is consistent with the reverse regulation of methylation on gene expression.

\section{BMI-associated miRNA and protein characteristics}

To characterize the BMI-associated miRNA and protein expression, we also identified BMI-associated miRNA and protein via the PSW method. As for mature miRNA expression, we identified 1 in CESC, 3 in cholangiocarcinoma (CHOL), 9 in COAD, 2 in LIHC, 3 in rectum adenocarcinoma (READ), 17 in UCEC, and 23 in combined colorectal cancer (Supplementary Table S2). We obtained miRNA target information by integrating multiple miRNA-mRNA interaction databases based on 2 experimentally validated databases: miRTarBase and TarBase [32, 33] and 4 computationally predicted databases: miRanda, miRDB, miRecords, and TargetScan [34-37]. KEGG pathway enrichment analysis of miRNA target genes was applied, and we found that the function of miRNA-targeted pathways was similar and potential target genes of BMI-related miRNAs were significantly enriched in tumor-related signaling and cell proliferation pathways such as the PI3K-AKT signaling pathway (Fig. 4, Figure S2B).

For RPPA protein expression, we identified 6 BMIrelated proteins (YWHAE, FN1, PRDX1, PRKCA, BAK1, and ANXA7) only in ESCA (Supplementary Table S2). Previously study report Mapk14-Ywhae signaling disorders in obese rats pancreas and increased YWHAE signaling promotes esophageal squamous carcinoma cell invasion [38, 39]. Dysregulated FN1 was identified in obese adipose tissue while high FN1 expression was associated with esophageal cancer [40, 41].

\section{BMI-associated somatic mutations and copy-number alteration characteristics}

We next identified BMI-associated genomic level patterns. We focused on somatic mutations in each cancer type to identify BMI-associated mutation patterns using the PSW method. Four mutated genes were found in ESCA, 5 were found in SKCM, and 13 were found in UCEC (Supplementary Table S2). Among them, SYNE1, SAMD9L, and KMT2C were overweight-biased genes and LRP2 was normal-biased genes in ESCA, EPPK1, MORC1, REV3L, USP34, and ZNF831 were overweightbiased genes in SKCM, MED12, and WDR87 were overweight-biased while DYRK1A, AHNAK, ATP2B3, NFE2L2, CEP290, REV3L, MUC5B, VPS13A, TTN, DHAH1, and SDK1 were normal-biased genes in UCEC (Fig. 5).

To identify BMI-associated somatic copy-number alternations (SCNA), we analyzed the significant SCNA identified by GISTIC in each cancer type at focal level amplifications/deletions and identified BMI-associated SCNA in five tumor types. 3p14.2 and 18q21.2 deletion were normal-weight-biased in CESC; 10q26.1 deletion was excess-weight-biased in CHOL; 3p22.1 deletion was excess-weight-biased in KIRP; 17q25.3 amplification was excess-weight-biased in LIHC; 3p14.1 amplification, $16 q 22.3,16 q 23.1$, and $17 q 21.31$ deletion were excessweight-biased in UCEC and 5q23.3 deletion; and 7p21.3 amplification were excess-weight-biased in combined 


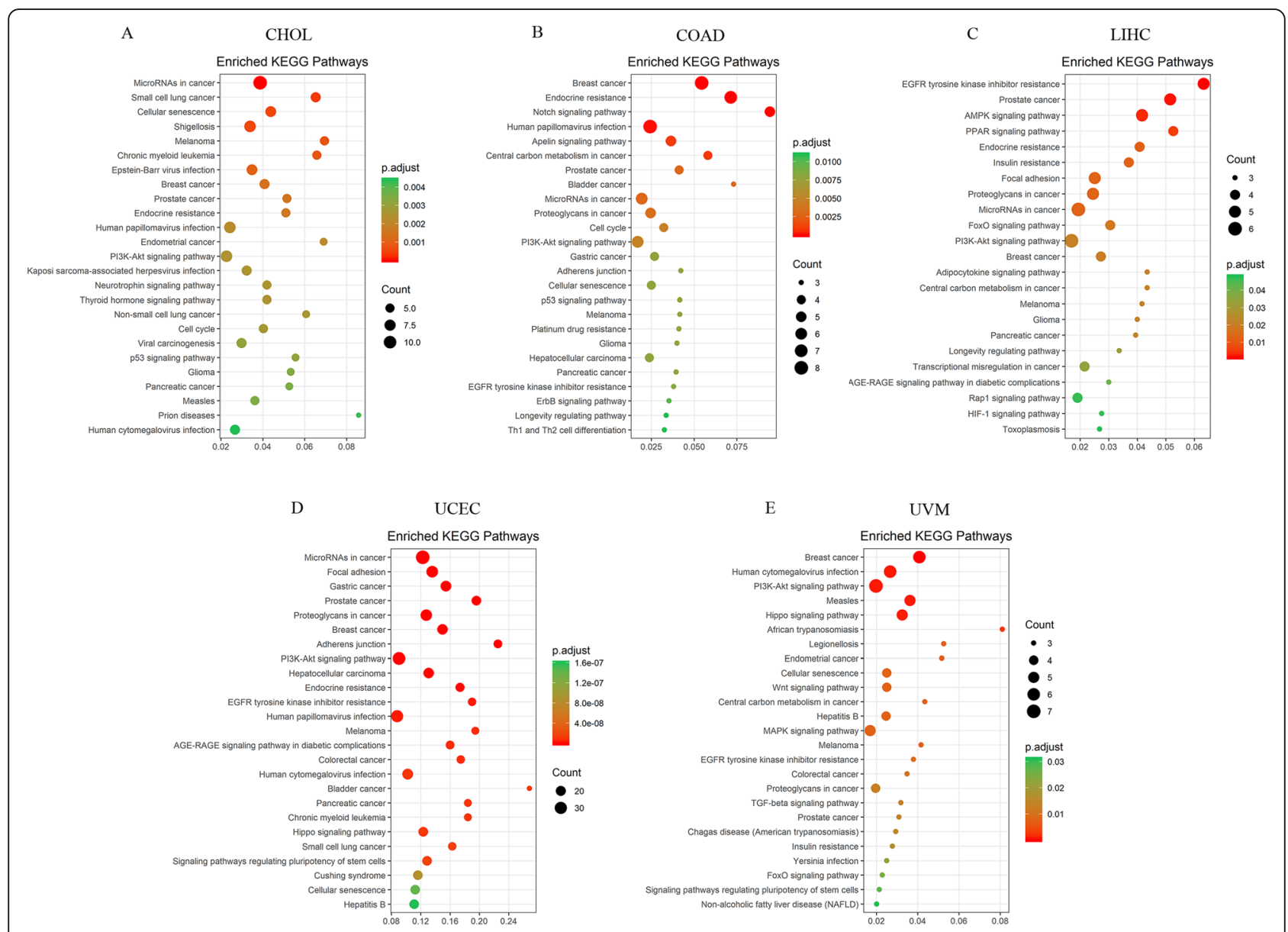

Fig. 4 Enriched pathways of BMl-associated miRNA targets. The top-enriched KEGG pathways of BMI-related miRNA potential target genes in a CHOL, b COAD, c LIHC, d UCEC, and e UVM

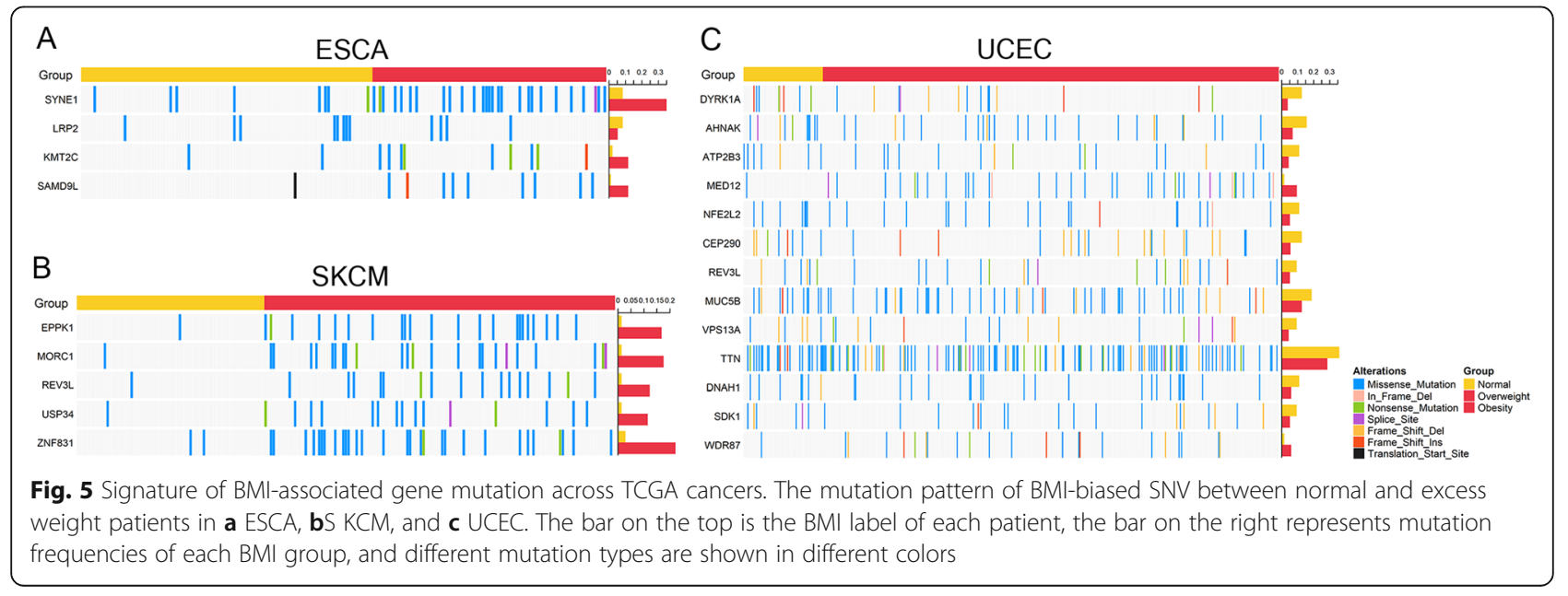


colorectal cancer at FDR $=0.1$ (Fig. 6, Figure S2C, Supplementary Table S2). To understand the mechanism underlying BMI-related SCNA, we next examined enriched pathways of amplified or deleted genes and the result showed that copy number abnormal genes enriched in some critical biological process pathways, such as cell growth and differentiation pathways in CESC, protein translation process, and myeloid cell differentiation in KIRP, glucometabolic process, and epidermal growth factor receptor signaling in LIHC, cyclin-depend kinase activity in UCEC deletion genes (Figure S3).

\section{BMI associated with tumor molecular subtypes in LIHC and UCEC}

The analysis of different molecular levels data showed that there were significant molecular differences in different BMI levels in particular tumor types, it is possible that obesity is associated with tumor molecular subtypes. So we compared the BMI difference between tumor subtypes and found that BMI distribution was significantly different only in LIHC and UCEC molecular subtypes
(Figure S4A-B). The iCluster1 of the LIHC showed a low BMI feature [42]. The signature genes of the POLE subtype with the lowest BMI involved in cellular metabolism, while the $\mathrm{CN}$-low subtype showed increased progesterone receptor expression [43]. It is interesting that the low BMI subtype has low CTNNB1 mutation frequency in LIHC, and the high BMI subtype has high CTNNB1 mutation frequency and the effects of the WNT-CTNNB1 pathway alterations on colorectal cancer outcome are modified by BMI and physical activity [44].

\section{The association between BMI and tumor immune microenvironment}

To study the association between BMI and tumor immune microenvironment, we first obtained genes related to specific tumor-infiltrating lymphocytes described in the previous study, which include 28 immune cell types [31]. Considering the effect of tumor purity on immune cell infiltration, we compared the purity between different BMI groups and no statistically significant difference was observed (Figure S4B). We then compared the
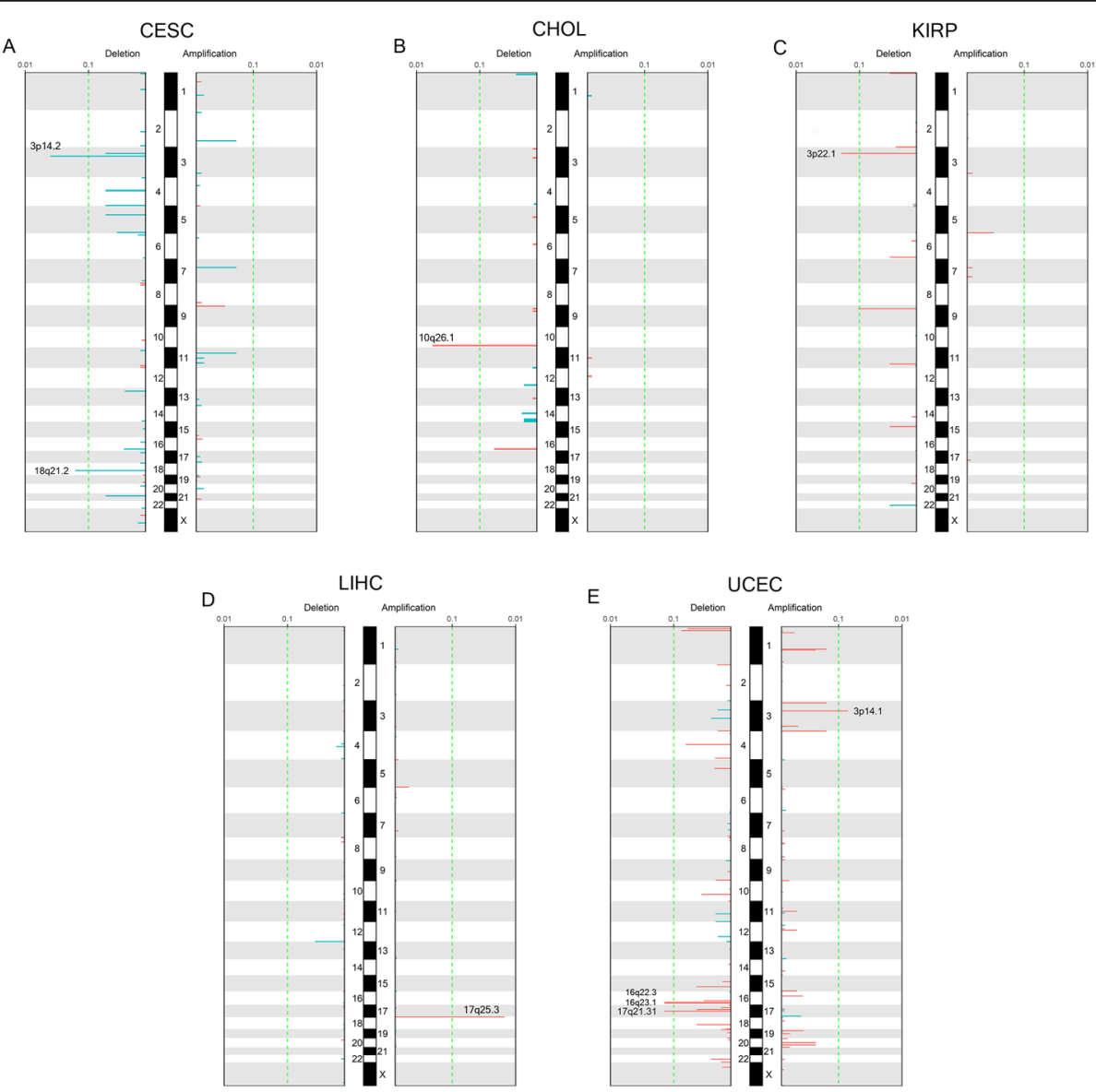

Fig. 6 Signature of BMI-associated genome SCNV across TCGA cancers. The SCNV pattern of BMI-biased focal amplification/deletion in a CESC, $\mathbf{b}$ $\mathrm{CHOL}, \mathbf{c} \mathrm{KIRP}, \mathbf{d} \mathrm{LIHC}$, and e UCEC. Each significant SCNA is annotated 
composite expression of each gene subset, which represents distinct immune cell subpopulations, in different BMI groups and estimated tumor-infiltrating lymphocytes from TCGA expression data by both single-sample gene set enrichment analysis (ssGSEA) and CIBERSORT approaches [45, 46]. Fifteen of 28 immune cell types showed significantly different expressions in different BMI groups across all cancer types. Among them, only two immune cell subpopulations (central memory CD4 $\mathrm{T}$ cell and plasmacytoid dendritic cell) showed a positive correlation with BMI, while the others were negatively correlated (Fig. 7a). For individual tumor types, we also observed multiple immune cell subpopulation expression differences in CESC, ESCA, LIHC, and UCEC (Figure S5).

Using the ssGSEA strategy, we estimated the 28 immune cell subpopulations in the tumor microenvironment of individual patients. For each immune cell subpopulation of each tumor type, we compared the enrichment and survival difference between normal weight and excess weight patients. We found that the enrichment status of more than one immune cell subpopulation is different between normal weight and excess weight patients in CESC, ESCA, LIHC, THYM, and UCEC (Fig. 7b).

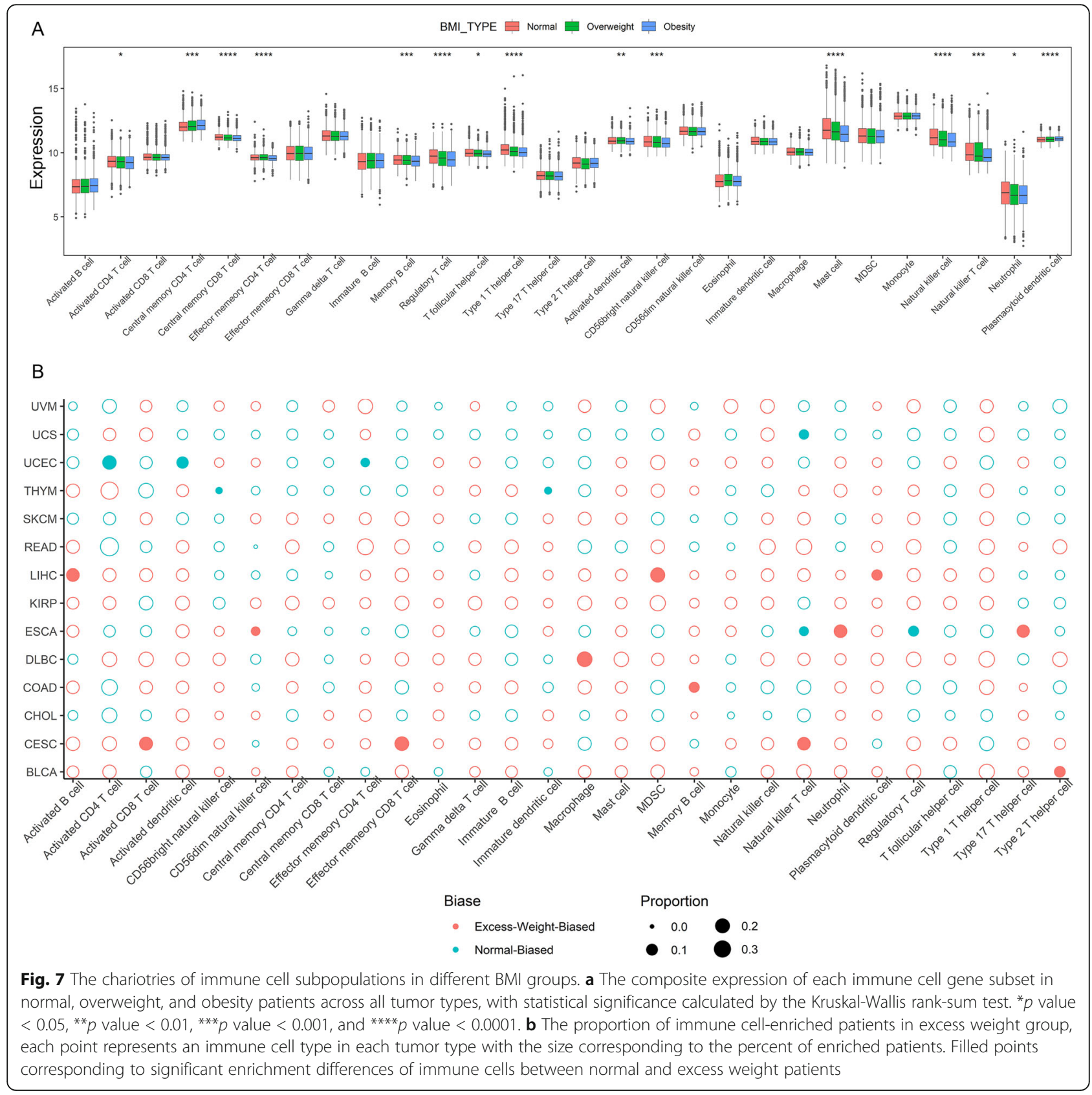


The fractions of 22 immune cell subpopulations identified by CIBERSORT were obtained from a previous study [47]. We then analyzed the association between BMI and tumor immune microenvironment. BMI was positively correlated with activated NK cells and CD8 T cells in CESC, activated mast cell, monocytes, resting memory CD4 $\mathrm{T}$ cells in ESCA, neutrophils in KIRP, resting dendritic cells and $\mathrm{T}$ regulatory cells in UCEC, follicular helper T Cells in UVM, but BMI was negatively correlated with M1 macrophages and M2 macrophages in ESCA, follicular helper T Cells in UCEC (Figure S6).

The immune cell types assessed by ssGSEA and CIBERSORT were not completely consistent, but we also found that the CD8 T cell in CESC was positively correlated with BMI in both methods. The above data suggested that BMI may play an important role in tumor immune microenvironment and may affect the different responses of cancer immunotherapy in the clinic.

\section{The association of BMI with different tumor metabolic pathways}

To gain a penetrating view of metabolic heterogeneity in different BMI groups, we obtained the gene sets of seven metabolic super-pathways based on the Reactome database [48]. Seven metabolic pathways include amino acid metabolism pathway with 348 genes, carbohydrate metabolism pathway with 286 genes, energy metabolism pathway with 110 genes, lipid metabolism pathway with 766 genes, nucleotide metabolism pathway with 90 genes, tricarboxylic acid (TCA) cycle pathway with 148 genes, and vitamin-cofactor metabolism pathways with 168 genes. We compared the composite expression of each gene subset among different BMI group samples and found differential expression in carbohydrate, energy, lipid, nucleotide, and vitamin-cofactor metabolism pathways (Fig. 8a). For individual tumor types, we found differential expression metabolism pathways in BLCA, COAD, ESCA, KIRP, READ, and UCEC (Figure S7).

We also estimated this seven metabolism pathway enrichment of individual patients using the ssGSEA method. In 8 cancer types, we found at least one differential enrichment metabolic pathway between normal and excess weight groups (Fig. 8b).

\section{BMI-related molecular signatures in clinically actionable genes}

To investigate the clinical implications BMI-related molecular signatures, we focus on a set of clinically actionable genes, which are the targets of FDA-approved anti-cancer drugs [49]. We selected our BMI-related clinically actionable genes following two criteria: (1) the target genes were contained in BMI-related genes and (2) the drugs of the targets were recorded as being able to be used for cancer treatment. We found 44 drugs target in 14 clinically actionable genes across different tumor types (Fig. 9). These 44 drugs can be categorized into four groups: chemotherapy, hormone therapy, immunotherapy, and targeted therapy. Previous studies reported PDGFRs as adipogenesis negative regulators and were associated with tumor stroma and survival [50, 51], and their biases in different BMI groups may suggest treatment response differences with olaratumab or dasatinib. Chronic myeloid leukemia observed significant obesity gain after imatinib treatment [52]. These results highlight the clinical importance of considering BMIassociated molecular signatures in precision medicine.

\section{Discussion}

Although the effect of overweight or obesity on tumor incidence, prognosis, and treatment responses has been reported in many kinds of literature, the molecular basis has remained unclear. Our study applied a comprehensive pan-cancer analysis that aimed to found BMI-related molecular differences across different cancer types and systematically catalogs the molecular signatures related to the BMI effect from genome to transcriptome to proteome level. We found colorectal, esophageal, and endometrial cancer were strong BMI-effect based on abundant molecular signatures in multidimensional data. Some of the BMI-correlated genes identified in this study have also been reported in different tumors by previous studies. For example, we identified BMI-correlated genes AKAP5 and JMJD5 in CESC, while it was reported that knockdown AKAP5 inhibited ERK1/2 activity and downregulation JMJD5 suppresses oral squamous cell carcinoma metastasis and induces apoptosis via p53/NF-kB pathway [53, 54].

Enrichment analysis shows that BMI-related genes are enriched in some important tumorigenesis and cancer development pathways, such as cell adhesion, cell proliferation, intracellular signaling, and specific tumor pathways. BMI-related genes enriched in p53 signaling pathways in UCEC, as it was reported that diet-induced obesity synergized with p53 mutation promoted hepatocarcinogenesis in zebrafish [55]. TP53 positivity was associated with shorter cancer-specific survival in nonobese patients, and breast and prostate cancer cells with mutant p53 increased oncogenic insulin effects [56,57]. Obese tumors patients with PI3K pathway mutant had a trend toward favorable outcomes [58]. GSEA analysis result indicated that signaling processing, metabolism, and immune response are the main BMI-affected pathways class in tumors. Previously, a study reported IGF system played an essential role in esophageal cancer malignant progression and association with visceral obesity [59]. Our study found IGF1R and some other IGF family genes significantly correlated with BMI of esophageal cancer patients, indicating the IGF pathway might be played a differential role in tumor progression between obesity and normal body weight 


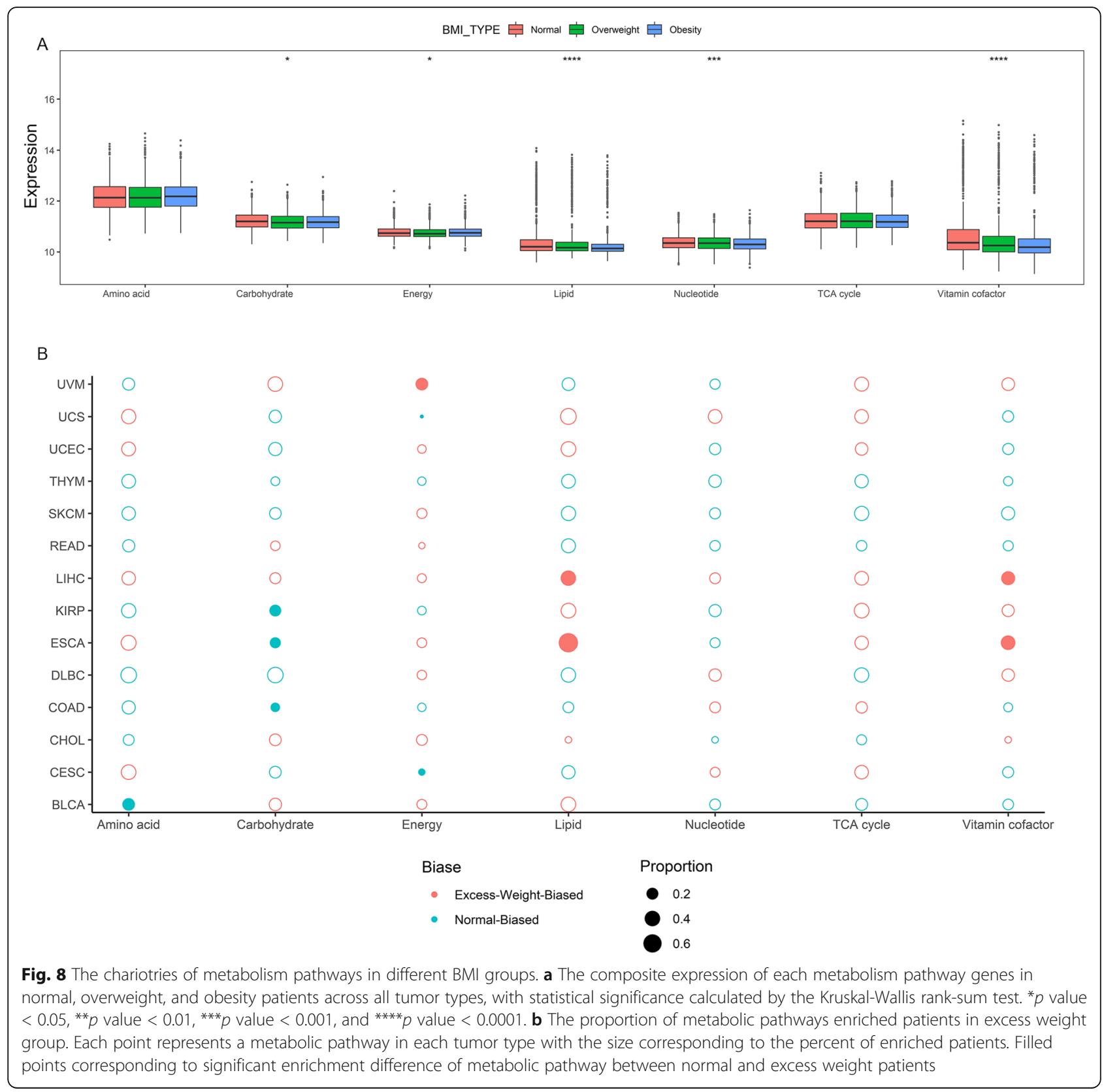

esophageal cancer patients. Global DNA methylation differential analysis of esophageal tumor showed differential methylation genes between different BMI groups involved in cell adhesion molecules, Wnt signaling, and growth hormone response, while our result showed a significant difference in cell adhesion, PI3K-AKT signaling, and Ras signaling pathways between the different BMI level patients [60]. Obesity is a risk factor strongly associated with endometrial cancer. Our study reveals that BMI-related genes were involved in the cell cycle, cell junction pathways, and significantly correlated with hormone receptor PGR in endometrial carcinoma. Previously researches reported the functions of adipose tissue in hormone production, inflammatory responses, and cellular proliferation pathways, while adipokines regulate cellular communication via gap junction loci $[61,62]$. And the hormone receptor ER and PR were significantly low express after bariatric surgery in endometrial and reduced cancer risk [63].

Obesity is a risk factor strongly related to tumor immune, inflammation, and metabolism. Previously, research demonstrated the association between obesity and immune aging, tumor progression, and PD-1mediated $\mathrm{T}$ cell dysfunction and increased efficacy of 


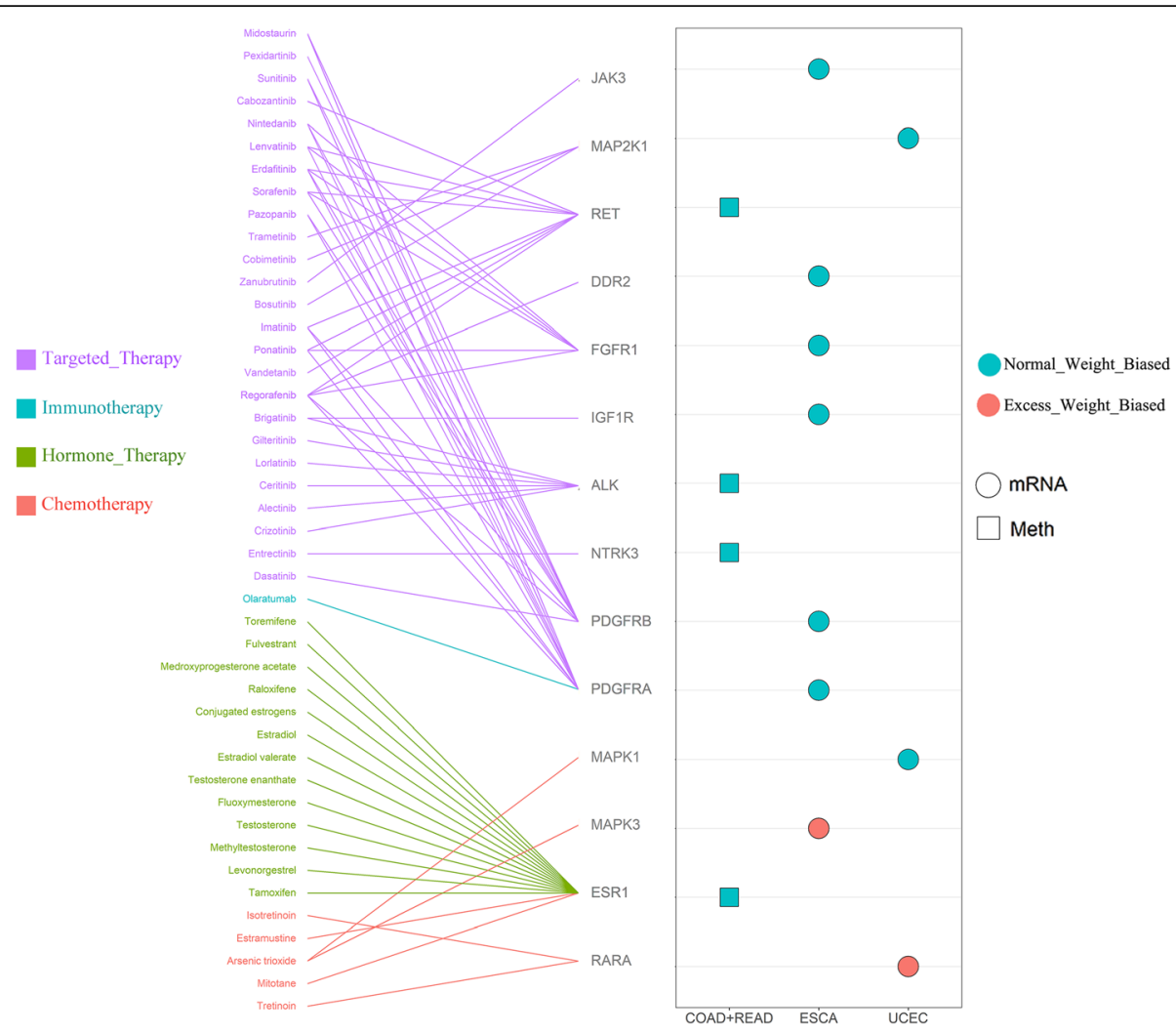

Fig. 9 Signature of BMI-related clinically actionable genes and FDA-approved drugs. The target relationship between FDA-approved anti-cancer drugs and corresponding clinically actionable genes (left) and the observed BMI-associated clinically actionable genes in each tumor type (right). A different color of symbols indicated different shapes of symbols indicated BMI groups and molecular models

PD-1/PD-L1 blockade in tumors [11]. Obesity-associated inflammation in cancer associated with multiple immune cell subsets such as natural killer cells, macrophages, and $\mathrm{T}$ cells [64]. Moreover, the presence of a $\mathrm{B}$ cell is related to good immunotherapy response in sarcoma and melanoma [65, 66]. Our study found the enrichment difference in multiple types of immune cells, such as $\mathrm{T}$ cell, the natural killer cell in cervical cancer, B cell in liver cancer, and natural killer $\mathrm{T}$ cell in uterine carcinosarcoma. This may be relevant to the immunotherapy response difference in obesity patients.

\section{Conclusions}

Our results provide a valuable starting point from which BMI effects should be explicitly considered in future clinical investigations and oncotherapy. Since TCGA clinical information may not be complete and rigorously annotated, approximately only 2700 patients recorded their BMI information across 14 cancer types. Future studies about this topic should conduct analysis larger cancer patient cohort and more tumor types, and the effects of BMI caused normal tissue to alter, and other potential confounding factors should be taken into consideration, as well as the efforts of assessing the clinical utility of the identified BMI-associated signatures.

\section{Supplementary information}

Supplementary information accompanies this paper at https://doi.org/10. 1186/s40170-020-00225-6.

Additional file 1: Figure S1. The association between BMI and survival by Multivariate COX analysis. Figure S2. Methylation, miRNA and SCNV characteristic in CORE. Figure S3. Pathway enrichment of BMI-biased SCNV signature. Figure S4. The association between BMI and tumor subtype or purity. Figure S5. The chariotries of immune cell subpopulations in different BMl groups of each tumor type. Figure S6. Chariotries of CIBERSORT identified immune cell subpopulations in different BMI groups of each tumor type. Figure S7. The chariotries of metabolism pathways in different BMl groups of each tumor type.

Additional file 2: Table S1. BMI characteristics of TCGA samples.

Additional file 3. The BMI-related genes.

\section{Abbreviations}

TCGA: The Cancer Genome Atlas; BMI: Body mass index (BMI); CDR: Clinical Data Resource; MAPK: Mitogen-activated protein kinases; SCNA: Somatic copy-number alternations; ssGSEA: Single-sample gene set enrichment analysis; NES: Normalized enrichment score 


\section{Acknowledgements}

Not applicable.

\section{Authors' contributions}

$\mathrm{CH}, \mathrm{XC}, \mathrm{CY}, \mathrm{GZ}, \mathrm{HX}$, and JX designed the study. CH mainly perform the analysis and wrote the paper. $\mathrm{YL}$ and $\mathrm{HX}$ supported on some data analysis and review the manuscript. GZ, HX, and JX provide the funding support. The authors read and approved the final manuscript.

\section{Funding}

This work was supported by grants from the National Natural Science Foundation of China $(81772590,81972233)$, Overseas Young Talents Project of China, "Innovative and Entrepreneurial Team" (No.(2018)2015) and Science and Technology Grant (BE2019758) of Jiangsu Province; Southeast UniversityNanjing Medical University Cooperative Research Project (2242018K3DN33) and Beijing Xisike Clinical Oncology Research Foundation (YBMS2019-071).

\section{Availability of data and materials}

The datasets used and/or analyzed during the current study are available from the corresponding author on reasonable request.

\section{Ethics approval and consent to participate}

Not applicable.

\section{Consent for publication}

We have obtained consent to publish this paper from all the participants.

\section{Competing interests}

The authors declare that they have no competing interests.

\section{Author details}

'Department of Pathology in the School of Basic Medical Sciences \& The Affiliated Sir Run Run Hospital \& State Key Laboratory of Reproductive Medicine \& Key Laboratory of Antibody Technique of National Health Commission, Nanjing Medical University, Nanjing 211166, China. ${ }^{2}$ The First Affiliated Hospital of Wenzhou Medical University, Wenzhou 325000, China. ${ }^{3}$ The Affiliated Cancer Hospital of Nanjing Medical University \& Jiangsu Cancer Hospital \& Jiangsu Institute of Cancer Research, Nanjing 210009 China. ${ }^{4}$ Department of Endocrinology, Sir Run Run Hospital, Nanjing Medical University, Nanjing 211166, China.

Received: 30 March 2020 Accepted: 2 September 2020

Published online: 25 September 2020

\section{References}

1. Bluher M. Obesity: global epidemiology and pathogenesis. Nat Rev Endocrinol. 2019:15:288-98.

2. Lauby-Secretan B, Scoccianti C, Loomis D, Grosse Y, Bianchini F, Straif K, International Agency for Research on Cancer Handbook Working G. Body fatness and cancer--viewpoint of the IARC working group. N Engl J Med. 2016:375:794-8.

3. Yu D, Zheng W, Johansson M, Lan Q, Park Y, White E, Matthews CE, Sawada N, Gao YT, Robien K, et al. Overall and central obesity and risk of lung cancer: a pooled analysis. J Natl Cancer Inst. 2018;110:831-42.

4. Vidal AC, Freedland SJ. Obesity and prostate cancer: a focused update on active surveillance, race, and molecular subtyping. Eur Urol. 2017;72:78-83.

5. Yang L, Drake BF, Colditz GA. Obesity and other cancers. J Clin Oncol. 2016; 34:4231-7.

6. Renehan AG, Tyson M, Egger M, Heller RF, Zwahlen M. Body-mass index and incidence of cancer: a systematic review and meta-analysis of prospective observational studies. Lancet. 2008;371:569-78.

7. Incio J, Ligibel JA, McManus DT, Suboj P, Jung K, Kawaguchi K, Pinter M, Babykutty S, Chin SM, Vardam TD, et al. Obesity promotes resistance to antiVEGF therapy in breast cancer by up-regulating IL-6 and potentially FGF-2. Sci Transl Med. 2018;10(432):eaag0945.

8. Lehuede C, Li X, Dauvillier S, Vaysse C, Franchet C, Clement E, Esteve D, Longue M, Chaltiel L, Le Gonidec S, et al. Adipocytes promote breast cancer resistance to chemotherapy, a process amplified by obesity: role of the major vault protein (MVP). Breast Cancer Res. 2019;21(1):7.
9. Su F, Ahn S, Saha A, DiGiovanni J, Kolonin MGA-Ohoo. Adipose stromal cell targeting suppresses prostate cancer epithelial-mesenchymal transition and chemoresistance. Oncogene. 2019;38(11):1979-88.

10. Incio J, Liu H, Suboj P, Chin SM, Chen IX, Pinter M, Ng MR, Nia HT, Grahovac J, Kao S, et al. Obesity-induced inflammation and desmoplasia promote pancreatic cancer progression and resistance to chemotherapy. Cancer Discov. 2016;6:852-69.

11. Wang Z, Aguilar EG, Luna JI, Dunai CA-Ohoo, Khuat LT, Le CT, Mirsoian A, Minnar CM, Stoffel KM, Sturgill IR, et al. Paradoxical effects of obesity on T cell function during tumor progression and PD-1 checkpoint blockade. Nat Med. 2019;25(1):141-51.

12. McQuade JL, Daniel CR, Hess KR, Mak C, Wang DY, Rai RR, Park JJ, Haydu LE, Spencer C, Wongchenko M, et al. Association of body-mass index and outcomes in patients with metastatic melanoma treated with targeted therapy, immunotherapy, or chemotherapy: a retrospective, multicohort analysis. Lancet Oncol. 2018;19(3):310-22.

13. Hopkins BD, Goncalves MD, Cantley LC. Obesity and cancer mechanisms: cancer metabolism. J Clin Oncol. 2016;34:4277-83.

14. Deng T, Lyon CJ, Bergin S, Caligiuri MA, Hsueh WA. Obesity, inflammation, and cancer. Annu Rev Pathol. 2016;11:421-49.

15. lyengar NM, Gucalp A, Dannenberg AJ, Hudis CA. Obesity and cancer mechanisms: tumor microenvironment and inflammation. J Clin Oncol. 2016;34:4270-6.

16. Renehan AG, Zwahlen M, Egger M. Adiposity and cancer risk: new mechanistic insights from epidemiology. Nat Rev Cancer. 2015;15:484-98.

17. Lumeng CN, Bodzin JL, Saltiel AR. Obesity induces a phenotypic switch in adipose tissue macrophage polarization. J Clin Invest. 2007;117:175-84.

18. O'Sullivan J, Lysaght J, Donohoe CL, Reynolds JV. Obesity and gastrointestinal cancer: the interrelationship of adipose and tumour microenvironments. Nat Rev Gastroenterol Hepatol. 2018;15:699-714.

19. Kolb R, Phan L, Borcherding N, Liu Y, Yuan F, Janowski AM, Xie Q, Markan KR, Li W, Potthoff MJ, et al. Obesity-associated NLRC4 inflammasome activation drives breast cancer progression. Nat Commun. 2016;7:13007.

20. Chen $\mathrm{H}, \mathrm{Hu} M, \mathrm{Xu} F, \mathrm{Xu} \mathrm{H}$, She J, Xia H. Understanding the inflammationcancer transformation in the development of primary liver cancer. Hepatoma Res. 2018:4(7):29.

21. Pollak M. Insulin and insulin-like growth factor signalling in neoplasia. Nat Rev Cancer. 2008:8:915-28.

22. Tsugane $\mathrm{S}$, Inoue $\mathrm{M}$. Insulin resistance and cancer: epidemiological evidence. Cancer Sci. 2010:101:1073-9.

23. Sung H, Siegel RL, Torre LA, Pearson-Stuttard J, Islami F, Fedewa SA, Goding Sauer A, Shuval K, Gapstur SM, Jacobs EJ, et al. Global patterns in excess body weight and the associated cancer burden. CA Cancer J Clin. 2019;69: 88-112.

24. Creighton CJ, Sada YH, Zhang Y, Tsimelzon A, Wong H, Dave B, Landis MD, Bear HD, Rodriguez A, Chang JC. A gene transcription signature of obesity in breast cancer. Breast Cancer Res Treat. 2012:132:993-1000.

25. Berg A, Hoivik EA, Mjos S, Holst F, Werner HM, Tangen IL, Taylor-Weiner A Gibson WJ, Kusonmano K, Wik E, et al. Molecular profiling of endometrial carcinoma precursor, primary and metastatic lesions suggests different targets for treatment in obese compared to non-obese patients. Oncotarget. 2015;6:1327-39.

26. Westin SN, Ju Z, Broaddus RR, Krakstad C, Li J, Pal N, Lu KH, Coleman RL, Hennessy BT, Klempner SJ, et al. PTEN loss is a context-dependent outcome determinant in obese and non-obese endometrioid endometrial cancer patients. Mol Oncol. 2015;9:1694-703.

27. Crujeiras AB, Diaz-Lagares A, Stefansson OA, Macias-Gonzalez M, Sandoval J, Cueva J, Lopez-Lopez R, Moran S, Jonasson JG, Tryggvadottir L, et al. Obesity and menopause modify the epigenomic profile of breast cancer. Endocr Relat Cancer. 2017;24:351-63.

28. Crujeiras AB, Morcillo S, Diaz-Lagares A, Sandoval J, Castellano-Castillo D Torres E, Hervas D, Moran S, Esteller M, Macias-Gonzalez M, et al. Identification of an episignature of human colorectal cancer associated with obesity by genome-wide DNA methylation analysis. Int J Obes (Lond). 2019; 43:176-88.

29. Sidaway P. Kidney cancer: methylation of obesity-related genes is associated with prognosis. Nat Rev Urol. 2017;14:452

30. Cancer Genome Atlas Research N, Weinstein JN, Collisson EA, Mills GB, Shaw KR, Ozenberger BA, Ellrott K, Shmulevich I, Sander C, Stuart JM. The Cancer Genome Atlas Pan-Cancer analysis project. Nat Genet 2013. 45:1113-20. 
31. Charoentong P, Finotello F, Angelova M, Mayer C, Efremova M, Rieder D, Hackl H, Trajanoski Z. Pan-cancer immunogenomic analyses reveal genotype-immunophenotype relationships and predictors of response to checkpoint blockade. Cell Rep. 2017;18:248-62.

32. Chou CH, Shrestha S, Yang CD, Chang NW, Lin YL, Liao KW, Huang WC, Sun TH, Tu SJ, Lee WH, et al. miRTarBase update 2018: a resource for experimentally validated microRNA-target interactions. Nucleic Acids Res. 2018:46:D296-302

33. Vlachos IS, Paraskevopoulou MD, Karagkouni D, Georgakilas G, Vergoulis T, Kanellos I, Anastasopoulos IL, Maniou S, Karathanou K, Kalfakakou D, et al. DIANA-TarBase $\mathbf{7} 7.0$ : indexing more than half a million experimentally supported miRNA:mRNA interactions. 2015;43(Database issue):D153-9.

34. Liu W, Wang X. Prediction of functional microRNA targets by integrative modeling of microRNA binding and target expression data. Genome Biol. 2019;20:18.

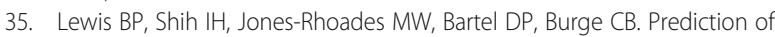
mammalian microRNA targets. Cell. 2003;115:787-98.

36. Xiao F, Zuo Z, Cai G, Kang S, Gao X, Li T. miRecords: an integrated resource for microRNA-target interactions. Nucleic Acids Res. 2009;37:D105-10.

37. Agarwal V, Bell GW, Nam JW, Bartel DP. Predicting effective microRNA target sites in mammalian mRNAs. Elife. 2015:4:e05005.

38. Yan S, Jiang Z, Cheng L, Lin Y, Fan B, Luo L, Yan Y, Yang L, Shen X. TLR4 knockout can improve dysfunction of beta-cell by rebalancing proteomics disorders in pancreas of obese rats. Endocrine. 2020;67:67-79.

39. Wen-Jian $Y$, Song T, Jun T, Kai-Ying X, Jian-Jun W, Si-Hua W. NF45 promotes esophageal squamous carcinoma cell invasion by increasing Rac1 activity through 14-3-3epsilon protein. Arch Biochem Biophys. 2019;663:101-8.

40. Berger E, Heraud S, Mojallal A, Lequeux C, Weiss-Gayet M, Damour O, Geloen A. Pathways commonly dysregulated in mouse and human obese adipose tissue: FAT/CD36 modulates differentiation and lipogenesis. Adipocyte. 2015;4:161-80.

41. Song G, Liu K, Yang X, Mu B, Yang J, He L, Hu X, Li Q, Zhao Y, Cai X, Feng G. SATB1 plays an oncogenic role in esophageal cancer by up-regulation of FN1 and PDGFRB. Oncotarget. 2017;8:17771-84.

42. Cancer Genome Atlas Research Network. Electronic address wbe, Cancer Genome Atlas Research N: Comprehensive and integrative genomic characterization of hepatocellular carcinoma. Cell. 2017;169:1327-41 e1323.

43. Cancer Genome Atlas Research N, Kandoth C, Schultz N, Cherniack AD, Akbani R, Liu Y, Shen H, Robertson AG, Pashtan I, Shen R, et al: Integrated genomic characterization of endometrial carcinoma. Nature 2013, 497:67-73.

44. Morikawa T, Kuchiba A, Yamauchi M, Meyerhardt JA, Shima K, Nosho K, Chan AT, Giovannucci E, Fuchs CS, Ogino S. Association of CTNNB1 (betacatenin) alterations, body mass index, and physical activity with survival in patients with colorectal cancer. JAMA. 2011;305:1685-94.

45. Barbie DA, Tamayo P, Boehm JS, Kim SY, Moody SE, Dunn IF, Schinzel AC, Sandy P, Meylan E, Scholl C, et al. Systematic RNA interference reveals that oncogenic KRAS-driven cancers require TBK1. Nature. 2009;462:108-U122.

46. Newman AM, Liu CL, Green MR, Gentles AJ, Feng WG, Xu Y, Hoang CD, Diehn M, Alizadeh AA. Robust enumeration of cell subsets from tissue expression profiles. Nature Methods. 2015;12:453.

47. Thorsson V, Gibbs DL, Brown SD, Wolf D, Bortone DS, Ou Yang TH, PortaPardo E, Gao GF, Plaisier CL, Eddy JA, et al. The immune landscape of cancer. Immunity. 2019;51:411-2.

48. Jassal B, Matthews L, Viteri G, Gong C, Lorente P, Fabregat A, Sidiropoulos K, Cook J, Gillespie M, Haw R, et al. The reactome pathway knowledgebase. Nucleic Acids Res. Nucleic Acids Res. 2020;48(D1):D498-503.

49. Van Allen EM, Wagle N, Stojanov P, Perrin DL, Cibulskis K, Marlow S, Jane-Valbuena J, Friedrich DC, Kryukov G, Carter SL, et al. Whole-exome sequencing and clinical interpretation of formalin-fixed, paraffinembedded tumor samples to guide precision cancer medicine. Nat Med. 2014:20:682-8.

50. Sun C, Sakashita H, Kim J, Tang Z, Upchurch GM, Yao L, Berry WL, Griffin TM, Olson LE. Mosaic mutant analysis identifies PDGFRalpha/PDGFRbeta as negative regulators of adipogenesis. Cell Stem Cell. 2020;26:707-21 e705.

51. Ostman A. PDGF receptors in tumor stroma: biological effects and associations with prognosis and response to treatment. Adv Drug Deliv Rev. 2017;121:117-23.

52. Aduwa E, Szydlo R, Marin D, Foroni L, Reid A, Goldman J, Apperley JF, Milojkovic D. Significant weight gain in patients with chronic myeloid leukemia after imatinib therapy. Blood. 2012;120:5087-8.
53. Gonzalez de Valdivia E, Broselid S, Kahn R, Olde B, LMF L-L. G proteincoupled estrogen receptor 1 (GPER1)/GPR30 increases ERK1/2 activity through PDZ motif-dependent and -independent mechanisms. J Biol Chem. 2017;292:9932-43.

54. Yao Y, Zhou WY, He RX. Down-regulation of JMJD5 suppresses metastasis and induces apoptosis in oral squamous cell carcinoma by regulating p53/ NF-kappaB pathway. Biomed Pharmacother. 2019;109:1994-2004.

55. Yang WY, Rao PS, Luo YC, Lin HK, Huang SH, Yang JM, Yuh CH. Omicsbased investigation of diet-induced obesity synergized with $\mathrm{HBx}$, Src, and p53 mutation accelerating hepatocarcinogenesis in Zebrafish model. Cancers (Basel). Cancers (Basel). 2019;11(12):1899.

56. Morikawa T, Kuchiba A, Liao X, Imamura Y, Yamauchi M, Qian ZR, Nishihara R, Sato K, Meyerhardt JA, Fuchs CS, Ogino S. Tumor TP53 expression status, body mass index and prognosis in colorectal cancer. Int J Cancer. 2012;131: 1169-78.

57. Valentino E, Bellazzo A, Di Minin G, Sicari D, Apollonio M, Scognamiglio G, Di Bonito M, Botti G, Del Sal G, Collavin L. Mutant p53 potentiates the oncogenic effects of insulin by inhibiting the tumor suppressor DAB2IP. Proc Natl Acad Sci U S A. 2017;114:7623-8.

58. Grigsby P, Elhammali A, Ruiz F, Markovina S, McLellan MD, Miller CA, Chundury A, Ta NL, Rashmi R, Pfeifer JD, et al. Clinical outcomes and differential effects of PI3K pathway mutation in obese versus non-obese patients with cervical cancer. Oncotarget. 2018;9:4061-73.

59. Doyle SL, Donohoe CL, Finn SP, Howard JM, Lithander FE, Reynolds JV, Pidgeon GP, Lysaght J. IGF-1 and its receptor in esophageal cancer: association with adenocarcinoma and visceral obesity. Am J Gastroenterol. 2012;107:196-204.

60. Kaz AM, Wong CJ, Varadan V, Willis JE, Chak A, Grady WM. Global DNA methylation patterns in Barrett's esophagus, dysplastic Barrett's, and esophageal adenocarcinoma are associated with BMI, gender, and tobacco use. Clin Epigenetics. 2016;8:111.

61. McDonald ME, Bender DP. Endometrial cancer: obesity, genetics, and targeted agents. Obstet Gynecol Clin North Am. 2019;46:89-105.

62. Polusani SR, Huang YW, Huang G, Chen CW, Wang CM, Lin LL, Osmulski P, Lucio ND, Liu L, Hsu YT, et al. Adipokines deregulate cellular communication via epigenetic repression of gap junction loci in obese endometrial cancer. Cancer Res. 2019;79:196-208.

63. Mackintosh ML, Derbyshire AE, McVey RJ, Bolton J, Nickkho-Amiry M, Higgins CL, Kamieniorz M, Pemberton PW, Kirmani BH, Ahmed B, et al. The impact of obesity and bariatric surgery on circulating and tissue biomarkers of endometrial cancer risk. Int J Cancer. 2019;144:641-50.

64. Conroy MJ, Dunne MR, Donohoe CL, Reynolds JV. Obesity-associated cancer: an immunological perspective. Proc Nutr Soc. 2016;75:125-38.

65. Helmink BA, Reddy SM, Gao J, Zhang S, Basar R, Thakur R, Yizhak K, SadeFeldman M, Blando J, Han G, et al. B cells and tertiary lymphoid structures promote immunotherapy response. Nature. 2020;577(7791):549-55.

66. Petitprez F, de Reynies A, Keung EZ, Chen TW, Sun CM, Calderaro J, Jeng YM, Hsiao LP, Lacroix L, Bougouin A, et al. B cells are associated with survival and immunotherapy response in sarcoma. Nature. 2020;577(7791): $556-60$

\section{Publisher's Note}

Springer Nature remains neutral with regard to jurisdictional claims in published maps and institutional affiliations.

Ready to submit your research? Choose BMC and benefit from:

- fast, convenient online submission

- thorough peer review by experienced researchers in your field

- rapid publication on acceptance

- support for research data, including large and complex data types

- gold Open Access which fosters wider collaboration and increased citations

- maximum visibility for your research: over $100 \mathrm{M}$ website views per year

At $\mathrm{BMC}$, research is always in progress.

Learn more biomedcentral.com/submission 